\title{
HEDGEHOG SIGNALING IN CHOLANGIOCYTES
}

\author{
Alessia Omenetti and Anna Mae Diehl \\ Division of Gastroenterology, Duke University Medical Center Durham, NC, USA
}

\begin{abstract}
Purpose of review-Cells lining the biliary tree are targets of injury, but also orchestrate liver repair. The latter involves autocrine/paracrine signaling that enhances the viability and growth of residual ductular cells and promotes accumulation of inflammatory and myofibroblastic cells. The mechanisms mediating this so-called "ductular reaction" need to be better understood to improve injury outcomes. Studies are revealing that ductular cells produce and respond to Hedgehog $(\mathrm{Hh})$ ligands, developmental morphogens that control progenitor cell fate and tissue construction during embryogenesis. Because this has potential implications for liver repair, this review will summarize current knowledge about Hh signaling and cholangiocytes.
\end{abstract}

Recent findings-Diverse types of liver injury stimulate cholangiocytes to generate Hh ligands, and cholangiocyte-derived Hh ligands interact with receptors on cholangiocytes and neighboring cells to modulate virtually every aspect of the ductular reaction to injury. Excessive Hh signaling promotes dysfunctional repair and results in chronic hepatic inflammation, fibrogenesis, and carcinogenesis.

Summary-The Hh pathway is part of the complex signaling network that orchestrates liver repair. How other pathways and post-transcriptional mechanisms modulate Hh signaling in ductular cells remains unclear. Further research in this area may identify novel therapeutic targets for the treatment of cholangiopathies and cholangiocarcinoma.

\section{Keywords}

hedgehog; liver progenitors; myofibroblasts; inflammation; cholangiocarcinoma

\section{INTRODUCTION}

Cells lining the biliary tree are major targets of diverse pathologic processes termed cholangiopathies. Once injured, ductular cells become reactive, and begin to play a pivotal role in the complex cellular cross talk that orchestrates liver tissue remodeling after disparate insults (1). One of the most important recent discoveries in this regard is the fact that cholangiocytes both produce and respond to Hedgehog (Hh) ligands, developmental morphogens that control progenitor cell fate and tissue construction during embryogenesis. Studies of cultured cells, diseased human liver samples, and their corresponding animal models are revealing the relevance of Hh signaling to cholangiocyte biology in healthy livers, as well as during liver injury, and the recovery phase after injurious insults have dissipated (Table 1). Hence, the objective of this review is to summarize current knowledge about Hh signaling and cholangiocytes.

Please Address Correspondence to: Anna Mae Diehl, MD, Chief, Division of Gastroenterology, Duke University School of Medicine, Snyderman Building (GSRB-1), 595 LaSalle Street, Durham, North Carolina 27710, 919-684-4173, diehl004@ mc.duke.edu.

Financial Disclosure: This work was supported by grants from the National Institutes of Health R01-DK077794 (to AMD), 


\section{THE HEDGEHOG PATHWAY: LESSONS FROM DEVELOPMENT TO UNDERSTAND ADULT TISSUE REMODELING}

In developing embryos, Hh ligands are produced by different types of cells at different stages of development. For example, cells in the primitive epiblast synthesize and release $\mathrm{Hh}$ ligands to instruct cell fate decisions that occur during gastrulation; later in development similar processes have been demonstrated in stem/progenitor cells that give rise to the thymus, bone marrow, blood vessels, skin, bone, and various internal organs. $(2,3)$ Although mapping of Hh ligand production and Hh-responsive cells has not been done systematically in developing liver, it is known that the ventral endoderm (which contains cells that eventually become hepatic progenitors) produces Sonic hedgehog (Shh) ligands in response to liver-specifying signals that are sent from the heart fields to instruct endodermal differentiation along the hepatic, as opposed to pancreatic, cell fate. (4) In addition, immature liver cells that rim the ductal plate have been shown to produce Hh ligands in human embryos, and Hh-responsive cells have been demonstrated along hepatic sinusoids at day 11.5 of mouse liver development. (5) Moreover, studies of cultures derived from clonal human stem/progenitor cells suggested that $\mathrm{Hh}$ signaling is required for optimal viability of such cells by demonstrating that treatment with the Hh signaling antagonist, cyclopamine, triggered dramatic increases in fetal progenitor cell apoptosis. (5)

In adult livers, progenitor cells are believed to reside along the canals of Hering. The latter are vestigial remnants of the ductual plate and constitute the most proximal aspect of the intrahepatic biliary tree. Adult liver progenitor cells are bi-potent, i.e., capable of giving rise to progeny that eventually differentiate into either hepatocytes or cholangiocytes. Human bipotent progenitors have been dubbed "hepatoblasts", while similar cells in mice have been designated as "oval cells" based on their appearance (small cell with an oval-shaped nucleus). (6) For the purpose of this review, we will refer to both rodent and human bipotent progenitor cells as hepatoblasts, and their heterogeneous, immature progeny as hepatoblastderivatives. Small hepatocytes and immature ductular cells are examples of hepatoblastderivatives. (Figure 1)

Both hepatoblasts and hepatoblast-derivatives from mice and humans have been shown to produce Hh ligands (e.g., Sonic hedgehog - Shh, or Indian hedgehog - Ihh) by immunohistochemistry and/or Western blot analysis of liver cell protein expression, as well as by real time PCR analysis of liver cell mRNAs. These cells are also likely to propagate (i.e., respond to) signals initiated by Hh ligands because similar approaches have demonstrated that they express Patched (Ptc), the receptor for Hh ligands, as well as members of the Glioblastoma (Gli) family of transcription factors.(7, 8) (Figure 1A)

Gli1, Gli2, and Gli3 are down-stream targets of the signal transduction pathway that is activated when $\mathrm{Hh}$ ligands bind to Patched, the plasma membrane spanning receptor for $\mathrm{Hh}$ ligands that controls the activation of Smoothened (Smo). In the absence of Hh ligands, Smo activity is repressed by Ptc, but binding of Hh ligands to Ptc relieves this repression and leads to propagation of intracellular signals that ultimately culminate in nuclear localization of Gli factors that trans-activate (generally via Gli1 and Gli2) or trans-repress (generally via a truncated form of Gli3) Hh-target gene expression (9). Hence, Hh-responsive cells can be identified by nuclear staining for Gli2, as well as by their expression of mRNAs for transcriptional targets of Gli2, such as Gli1, Hh interacting protein (Hhip), or ptc. (Figure 2) On the other hand, because other signaling pathways also control the expression of Hhregulated genes, and the function of Gli factors can be modulated by post-transcriptional mechanisms, various complementary approaches are generally required to confirm/refute the functional significance of Hh-initiated signals in any given cell (10). 
As detailed below, the biological relevance of Hh pathway in adult liver progenitors and certain other types of adult liver cells (e.g., hepatic stellate cells) has been demonstrated by pharmacologic and/or genetic approaches that blocked Hh ligands and/or inhibited Smo activation to affect significant changes in adult liver progenitor cell fate. Conversely, present evidence indicates that fully-mature hepatocytes are not Hh-responsive (5) (Figure 1A), although such cells do up-regulate production of Hh ligands when injured (11) (Figure 1B). The issue of Hh-responsiveness in mature cholangiocytes has been more difficult to resolve: technical issues plague efforts to achieve targeted interruption of $\mathrm{Hh}$ signaling in mature cholangiocytes residing in diverse parts of the adult biliary tree, and interpreting data generated by less-specific strategies is confounded by the fact that progenitors typically localize to the ductular compartment in adult livers. (Figure 1A-B)

Despite these challenges, loss- and gain-of-function approaches do support a role for $\mathrm{Hh}$ pathway activation in adult liver repair. Increased expression of Hh ligands and various Hhtarget genes has been demonstrated to occur following partial hepatectomy $(\mathrm{PH})$, which delivers a major stimulus for liver regeneration. Moreover, treating rodents with cyclopamine immediately after PH virtually abolished the typical post-PH expansion of cells expressing markers of hepatoblasts, prevented the normal compensatory increase in hepatocyte and cholangiocyte proliferation, and resulted in death of almost all of the mice within 72 h. (12) Dramatic increases in hepatic expression of Hh ligands and up-regulation of Hh pathway activity also occur during the cholestatic liver injury that follows bile duct ligation (BDL) in rodents. In this model, Hh pathway activation is accompanied by marked hepatic accumulation of ductular-type progenitor cells and myofibroblasts. Hh ligand production, pathway activation, and the other responses were shown to subside in parallel when biliary obstruction was reversed. (13) Moreover, mice with a genetic alteration that impairs silencing of Hh signaling exhibited exacerbated ductular and fibrogenic responses. (7) Similar injury-related induction of Hh ligand production and Hh pathway activity has been demonstrated after toxin-induced liver injury. In such models, hepatic accumulation of progenitors, myofibroblasts, and liver fibrosis correlate with the level of Hh pathway activation and are significantly amplified in animals with defects that result in excessive $\mathrm{Hh}$ pathway activity. (14-17) Hence, it has become important to characterize the types of cells that produce and respond to Hh ligands in injured adult livers. A growing body of experimental evidence implicates cholangiocytes as major players in these responses. Thus, the rest of the review will summarize that information.

\section{CHOLANGIOCYTES: A NEWLY DISCOVERED SOURCE OF HEDGEHOG LIGANDS}

Immunohistochemical analysis of healthy and diseased livers from children and adults demonstrates that ductular cells are capable of producing Shh and Ihh ligands. Hh ligand production is increased by various biliary stressors, including mechanical obstruction of large bile ducts (BDL), various genetic disorders that interfere with biliary transport (PFIC-1, PFIC-2, Alagille syndrome), presumptive/proven viral infection of bile duct cells (biliary atresia), and immune-mediated biliary attack (primary biliary cirrhosis, primary sclerosing cholangitis). $(7,8,18)$ Ductular-appearing cells also variably produce Hh ligands when hepatocytes are injured by toxins (e.g., ethanol, ethionine) $(11,19)$, nutritional factors (methionine-choline deficiency, obesity-related liver disease), (14-17) and/or viral infection (e.g., hepatitis B, hepatitis C). (20) Increased ductular cell production of Hh ligands has also been demonstrated in stromal tissue encapsulating nodules of hepatocellular carcinoma in patients with cirrhosis related to chronic viral hepatitis. (REF)

Cholangiocyte cell lines, such as Normal Rat Cholangiocytes-NRC1 and murine 603B, and primary cholangiocytes isolated from healthy adult rodents have been shown to express $\mathrm{Hh}$ 
ligand mRNAs and proteins by real time PCR and Western blot/immunocytochemistry, respectively $(7,21)$. Moreover, such cells release biologically-active Hh ligands that are capable of activating Smo-dependent signaling in other cells that have been stably transfected with Gli-luciferase reporter constructs. (22)

The mechanisms that regulate ductular cell production of Hh ligands are not well understood. As in hepatic stellate cells, (23) in cultured cholangiocytes, platelet derived growth factor (PDGF) BB (a factor that is produced by activated cholangiocytes) stimulates expression of Shh and inhibitors of PI3K and/or AKT act down-stream of PDGF-BB to inhibit this process. (13) In vitro activation of cholangiocytes with exogenous PDGF-BB induces production of exosomes containing biologically active Ihh and Shh ligands. These exosomes are released, allowing biliary cells to trigger Hh signaling in neighboring liver cells in a paracrine fashion.(22) Striking enrichment of plasma and bile with membraneassociated Hh ligands has been demonstrated to occur after insults, such as BDL, that activate cholangiocytes in situ, (22) raising the possibility that such liver-derived Hh ligands may also trigger Hh signaling in Hh-responsive cells that reside in other tissues that are immediately "down-stream" of the biliary or hepatic venous outflow (e.g., intestine, heart or lung). In many types of liver injury, myofibroblastic cells localize near ductular type cells, and transwell co-culture systems demonstrate that myofibroblastic cells produce soluble factors that activate Hh signaling in ductular cells, suggesting that paracrine mechanisms may also increase cholangiocyte expression of $\mathrm{Hh}$ target genes. Antibody neutralization studies demonstrate that such myofibroblast-derived factors include Hh ligands, but other factors (e.g., TGF beta) may also be involved $(7,13)$

\section{CHOLANGIOCYTE CILIUM AND RESPONSIVNESS TO HEDGEHOG SIGNALING}

Until relatively recently, the paradigm for Hh Pathway signaling posited cross-talk between two distinct compartments: 1) Hh ligand-producing cells (which are typically epithelial) and 2) Hh-responsive cells (which are generally mesenchymal). (9) However, evidence now supports an alternative model in which at least some of the ligand-producing epithelial cells are themselves Hh-responsive. As detailed above, cholangiocytes appear to be capable both of producing and responding to Hh ligands. Examination of primary ductular cells, cell lines, and liver tissues from rodents and humans has demonstrated that cholangiocytes not only produce Hh ligands but possess all the machinery required to transduce Hh signaling, including Ptc, Smo, and Gli family transcription factors. Moreover, various in vitro and in vivo manipulations of Hh pathway activity alter expression of Hh target genes and/or Glidependent transcriptional activity in ductular cells, proving that such cells are truly Hhresponsive.

Intriguingly, like other Hh-responsive vertebrate cells, cholangiocytes have a functional primary cilium, (24) which protrudes from the cell membrane and acts as Hh- signaling center. $(25,26)$ There is growing evidence that Smo localizes to the primary cilium during its activation, and that Ptc inhibits this event in the absence of Hh ligands. $(27,28)$ The Hh repressor Gli3 also localizes to cilia, and thus, ciliary disfunction can result in aberrant Gli3 localization and consequent repression of Hh signaling. (29) A link between Hh-dependent activation of Smo in the primary cilium, Gli2 trafficking and Gli2 -mediated transcriptional activation has also been demonstrated: recombinant Shh ligand caused Smo and Gli2 to accumulate within the cilium membrane and ciliary tip, respectively, and these events preceded and were necessary for Gli2 to traffick into the nucleus and trans-activate target genes. (30) Growing evidence that diverse inherited ciliary defects and acquired ciliopathies variably disrupt (i.e., either activate or repress) Hh signaling, further supports the importance of primary cilia in regulating Hh pathway activity in Hh-responsive cells (31, 
32). Although the role for ciliary events in cholangiocyte Hh-signal transduction remains unproven, a recent elegant study supports this concept by demonstrating that exosomes in bile interact with primary cilia to regulate cholangiocyte proliferation. (33)

\section{HEDGEHOG SIGNALING: KEY FOR ACQUISITION A “REACTIVE" PHENOTYPE OF INJURED CHOLANGIOCYTES}

The effects of Hh signaling on cholangiocyte phenotype have been extensively explored in the past few years. In healthy adult livers (where Hh signaling is barely detectable), cholangiocytes display a very low proliferative index and thus, are considered to be mitotically dormant. However, following biliary injury surviving cholangiocytes start proliferating and acquire the so called "reactive phenotype". (1) These reactive ductular epithelial cells are characterized as having the following features: 1) enhanced viability (reduced apoptosis/proliferation) that leads to expansion of ductular cell populations; 2) increased secretion of chemokines/cytokines that recruit immune cells and promote inflammation; 3) loss of epithelial features through induction of epithelial to mesenchymal transition (EMT) and/or blockage of epithelial differentiation; and 4) production of profibrogenic factors that activate and attract matrix producing myofibroblastic cells to promote biliary fibrosis. Expansion of the ductular cell compartment (i.e., reactive ductular cells and recruited immune and myofibroblatic cells) has been dubbed the ductular reaction to injury (Figure 3). Reactive biliary epithelial cells are believed to function as the pacemaker for biliary fibrosis. As detailed above, at least one of the factors generated by reactive cholangiocytes (PDGF-BB) causes both myofibroblasts and cholangiocytes to produce $\mathrm{Hh}$ ligands. The latter, in turn, robustly amplify all aspects of the reactive cholangiocyte phenotype. Thus, once released in the microenvironment, Hh ligands drive the acquisition/ perpetuation of a reactive phenotype in ductular cells, and hence, Hh pathway activation plays a pivotal role in determining the outcome of all conditions that result in cholangiocyte activation (i.e., a ductular reaction). The latter are now known to include various types of biliary tract disease in children and adults, as well as diverse types of parenchymal liver injury.

\section{HEDGEHOG SIGNALING AND CHOLANGIOCARCINOMA}

Given evidence that Hh signaling modulates the delicate balance between apoptosis and survival in cholangiocytes, it is conceivable that the Hh pathway is involved in the pathogenesis of cholangiocarcinoma. Indeed, the biological significance of Hh signaling is now accepted in several other types of cancer. Several years ago, Hh transcriptional activity was noted in some cholangiocarcinoma cell lines. (34) However, the potential significance of this finding was not evident until recently when it was demonstrated that expression of TRAIL and at least one of its death receptors (i.e. DR4) are controlled by Gli-family transcription factors. The Hh-inducible transcription factor, Gli3, engages the DR4 promoter and represses DR4 transcription. (35) Gli3 also enhances cholangiocyte accumulation of the anti-apoptotic factor, Mcl-1 by directly repressing transcription of miR-29b, a factor that normally promotes Mcl-1 degradation. (36) Thus, Hh pathway activation may help to promote the survival of cholangiocarcinoma cells. Evidence that such cells exhibit reduced expression of DR4 and enhanced accumulation of Mcl-1 supports this concept.

\section{CONCLUSION}

Within the last five-six years considerable evidence has accumulated which demonstrate that Hh signaling modulates a wide range of cholangiocyte responses to diverse physiological and pathological conditions. Hence, the Hh pathway merits inclusion in the complex signaling network that orchestrates cholangiocyte viability and differentiation. Hh signaling 
seems to be particularly important for acquisition of the immuonoregulatory and profibrogenic phenotype that typifies reactive ductular cells in injured livers. How other signaling pathways and post-transcriptional mechanisms modulate Hh pathway activation in ductular cells remains unclear. Further research in this area may identify novel therapeutic targets for the treatment of cholangiopathies and cholangiocarcinoma.

\section{References}

1. Alvaro D, Mancino MG. New insights on the molecular and cell biology of human cholangiopathies. Mol Aspects Med. 2008 Feb-Apr;29(1-2):50-7. [PubMed: 18230407]

2. Nagase T, Nagase M, Machida M, Yamagishi M. Hedgehog signaling: a biophysical or biomechanical modulator in embryonic development? Ann N Y Acad Sci. 2007 Apr.1101:412-38. [PubMed: 17332081]

3. Jiang J, Hui CC. Hedgehog signaling in development and cancer. Dev Cell. 2008 Dec; 15(6):80112. [PubMed: 19081070]

4. Deutsch G, Jung J, Zheng M, Lora J, Zaret KS. A bipotential precursor population for pancreas and liver within the embryonic endoderm. Development. 2001 Mar; 128(6):871-81. [PubMed: 11222142]

*5. Sicklick JK, Li YX, Melhem A, Schmelzer E, Zdanowicz M, Huang J, et al. Hedgehog signaling maintains resident hepatic progenitors throughout life. Am J Physiol Gastrointest Liver Physiol. 2006 May; 290(5):G859-70. First evidence that the hedgehog pathway promotes the viability of liver progenitors in both developing and adult livers. [PubMed: 16322088]

6. Zaret KS, Grompe M. Generation and regeneration of cells of the liver and pancreas. Science. 2008 Dec 5; 322(5907):1490-4. [PubMed: 19056973]

*7. Omenetti A, Yang L, Li YX, McCall SJ, Jung Y, Sicklick JK, et al. Hedgehog-mediated mesenchymal-epithelial interactions modulate hepatic response to bile duct ligation. Lab Invest. 2007 May; 87(5):499-514. Early evidence that reactivation of the hedgehog pathway occurs in injured bile ducts of adults. [PubMed: 17334411]

8. Jung Y, McCall SJ, Li YX, Diehl AM. Bile ductules and stromal cells express hedgehog ligands and/or hedgehog target genes in primary biliary cirrhosis. Hepatology. 2007 May; 45(5):1091-6. [PubMed: 17464985]

9. Varjosalo M, Taipale J. Hedgehog: functions and mechanisms. Genes Dev. 2008 Sep 15; 22(18): 2454-72. [PubMed: 18794343]

10. Jenkins D. Hedgehog signalling: emerging evidence for non-canonical pathways. Cell Signal. 2009 Jul; 21(7):1023-34. [PubMed: 19399989]

**11. Jung Y, Witek RP, Syn WK, Choi SS, Omenetti A, Premont R, et al. Signals from dying hepatocytes trigger growth of liver progenitors. Gut. 2010 May; 59(5):655-65. Identifies a mechanism by which liver injury activates hedgehog signaling in adults. [PubMed: 20427400]

*12. Ochoa B, Syn WK, Delgado I, Karaca GF, Jung Y, Wang J, et al. Hedgehog signaling is critical for normal liver regeneration after partial hepatectomy in mice. Hepatology. 2010 May; 51(5): 1712-23. First direct proof that an active hedgehog pathway is necessary for liver regeneration in adults. [PubMed: 20432255]

13. Omenetti A, Popov Y, Jung Y, Choi SS, Witek RP, Yang L, et al. The hedgehog pathway regulates remodelling responses to biliary obstruction in rats. Gut. 2008 Sep; 57(9):1275-82. [PubMed: 18375471]

14. Syn WK, Choi SS, Liaskou E, Karaca GF, Agboola KM, Oo YH, et al. Osteopontin is induced by hedgehog pathway activation and promotes fibrosis progression in nonalcoholic steatohepatitis. Hepatology. 2011 Jan; 53(1):106-15. [PubMed: 20967826]

15. Syn WK, Jung Y, Omenetti A, Abdelmalek M, Guy CD, Yang L, et al. Hedgehog-mediated epithelial-to-mesenchymal transition and fibrogenic repair in nonalcoholic fatty liver disease. Gastroenterology. 2009 Oct; 137(4):1478-88. e8. [PubMed: 19577569]

*16. Syn WK, Oo YH, Pereira TA, Karaca GF, Jung Y, Omenetti A, et al. Accumulation of natural killer T cells in progressive nonalcoholic fatty liver disease. Hepatology. 2010 Jun; 51(6):1998- 
2007. Identifies a novel mechanism for hepatic recruitment of NKT cells to injured livers and suggests a role for these cells in fibrogenesis. [PubMed: 20512988]

17. Jung Y, Diehl AM. Non-alcoholic steatohepatitis pathogenesis: role of repair in regulating the disease progression. Dig Dis. 2010; 28(1):225-8. [PubMed: 20460916]

18. Omenetti A, Diehl AM, Whitington PF. Hedgehog pathway activation in biliary atresia. Hepatology. In press.

19. Jung Y, Brown KD, Witek RP, Omenetti A, Yang L, Vandongen M, et al. Accumulation of hedgehog-responsive progenitors parallels alcoholic liver disease severity in mice and humans. Gastroenterology. 2008 May; 134(5):1532-43. [PubMed: 18471524]

20. de Pereira TA, Witek RP, Syn WK, Choi SS, Bradrick S, Karaca GF, et al. Viral factors induce Hedgehog pathway activation in humans with viral hepatitis, cirrhosis, and hepatocellular carcinoma. Lab Invest. 2010 Dec; 90(12):1690-703. [PubMed: 20697376]

*21. Omenetti A, Porrello A, Jung Y, Yang L, Popov Y, Choi SS, et al. Hedgehog signaling regulates epithelial-mesenchymal transition during biliary fibrosis in rodents and humans. J Clin Invest. 2008 Oct; 118(10):3331-42. Evidence for another mechanism by which Hedgehog signaling might expand myofibroblast populations in adult livers. [PubMed: 18802480]

**22. Witek RP, Yang L, Liu R, Jung Y, Omenetti A, Syn WK, et al. Liver cell-derived microparticles activate hedgehog signaling and alter gene expression in hepatic endothelial cells. Gastroenterology. 2009 Jan; 136(1):320-30. e2. First evidence that biologically active hedgehog ligands are released from mammalian cells in exosomes. [PubMed: 19013163]

**23. Yang L, Wang Y, Mao H, Fleig S, Omenetti A, Brown KD, et al. Sonic hedgehog is an autocrine viability factor for myofibroblastic hepatic stellate cells. J Hepatol. 2008 Jan; 48(1):98106. Proves that hedgehog pathway activation is required for optimal activation and growth of hepatic stellate cells, identifying the Hedgehog pathway as a novel mediator of liver fibrogenesis. [PubMed: 18022723]

24. Huang BQ, Masyuk TV, Muff MA, Tietz PS, Masyuk AI, Larusso NF. Isolation and characterization of cholangiocyte primary cilia. Am J Physiol Gastrointest Liver Physiol. 2006 Sep; 291(3):G500-9. [PubMed: 16899714]

25. Zeng H, Jia J, Liu A. Coordinated translocation of mammalian Gli proteins and suppressor of fused to the primary cilium. PLoS One. 2010 Dec.5(12):e15900. [PubMed: 21209912]

26. Barzi M, Kostrz D, Menendez A, Pons S. Sonic hedgehog induced proliferation requires specific G-alpha-inhibitory proteins. J Biol Chem. 2011 Jan 5.

27. Corbit KC, Aanstad P, Singla V, Norman AR, Stainier DY, Reiter JF. Vertebrate Smoothened functions at the primary cilium. Nature. 2005 Oct 13; 437(7061):1018-21. [PubMed: 16136078]

28. Rohatgi R, Milenkovic L, Scott MP. Patched1 regulates hedgehog signaling at the primary cilium. Science. 2007 Jul 20; 317(5836):372-6. [PubMed: 17641202]

29. May SR, Ashique AM, Karlen M, Wang B, Shen Y, Zarbalis K, et al. Loss of the retrograde motor for IFT disrupts localization of Smo to cilia and prevents the expression of both activator and repressor functions of Gli. Dev Biol. 2005 Nov 15; 287(2):378-89. [PubMed: 16229832]

30. Kim J, Kato M, Beachy PA. Gli2 trafficking links Hedgehog-dependent activation of Smoothened in the primary cilium to transcriptional activation in the nucleus. Proc Natl Acad Sci U S A. 2009 Dec 22; 106(51):21666-71. [PubMed: 19996169]

31. Veland IR, Awan A, Pedersen LB, Yoder BK, Christensen ST. Primary cilia and signaling pathways in mammalian development, health and disease. Nephron Physiol. 2009; 111(3):p39-53. [PubMed: 19276629]

32. Goetz SC, Ocbina PJ, Anderson KV. The primary cilium as a Hedgehog signal transduction machine. Methods Cell Biol. 2009; 94:199-222. [PubMed: 20362092]

33. Masyuk AI, Huang BQ, Ward CJ, Gradilone SA, Banales JM, Masyuk TV, et al. Biliary exosomes influence cholangiocyte regulatory mechanisms and proliferation through interaction with primary cilia. Am J Physiol Gastrointest Liver Physiol. 2010 Oct; 299(4):G990-9. [PubMed: 20634433]

34. Berman DM, Karhadkar SS, Maitra A, Montes De Oca R, Gerstenblith MR, Briggs K, et al. Widespread requirement for Hedgehog ligand stimulation in growth of digestive tract tumours. Nature. 2003 Oct 23; 425(6960):846-51. [PubMed: 14520411] 
*35. Kurita S, Mott JL, Almada LL, Bronk SF, Werneburg NW, Sun SY, et al. GLI3-dependent repression of DR4 mediates hedgehog antagonism of TRAIL-induced apoptosis. Oncogene. 2010 Aug 26; 29(34):4848-58. Elegant delineation of molecular mechanism by which hedgehogregulated transcription factors promote viability of malignant cholangiocytes. [PubMed: 20562908]

*36. Mott JL, Kurita S, Cazanave SC, Bronk SF, Werneburg NW, Fernandez-Zapico ME. Transcriptional suppression of mir-29b-1/mir-29a promoter by c-Myc, hedgehog, and NFkappaB. J Cell Biochem. 2010 Aug 1; 110(5):1155-64. This paper extends information about molecular mechanisms by which hedgehog-regulated transcription factors promote viability of malignant cholangiocytes. [PubMed: 20564213] 


\section{KEY POINTS}

1. Cholangiocytes are capable of producing and responding to Hedgehog, a developmental morphogen.

2. Hedgehog signaling induces cholangiocytes to acquire the immunoregulatory and pre-fibrogenic phenotype that typifies reactive ductular cells in injured livers.

3. Hedgehog signaling enhances the survival of malignant cholangiocytes.

4. The hedgehog pathway may be a therapeutic target in cholangiopathies and cholangiocarcinoma. 
Figure 1A

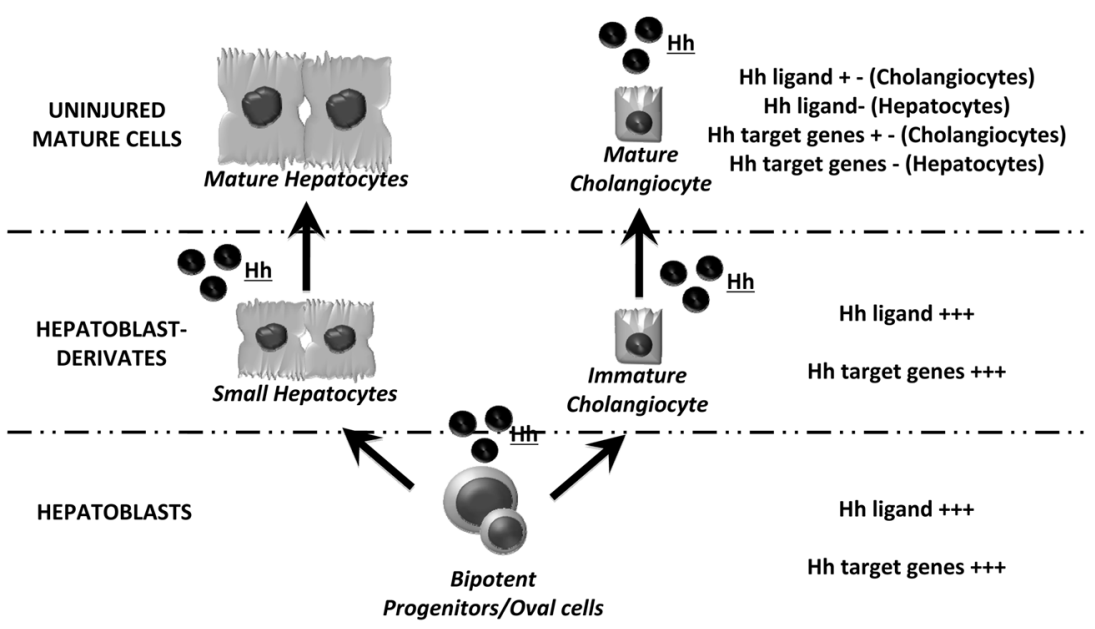

Figure 1B

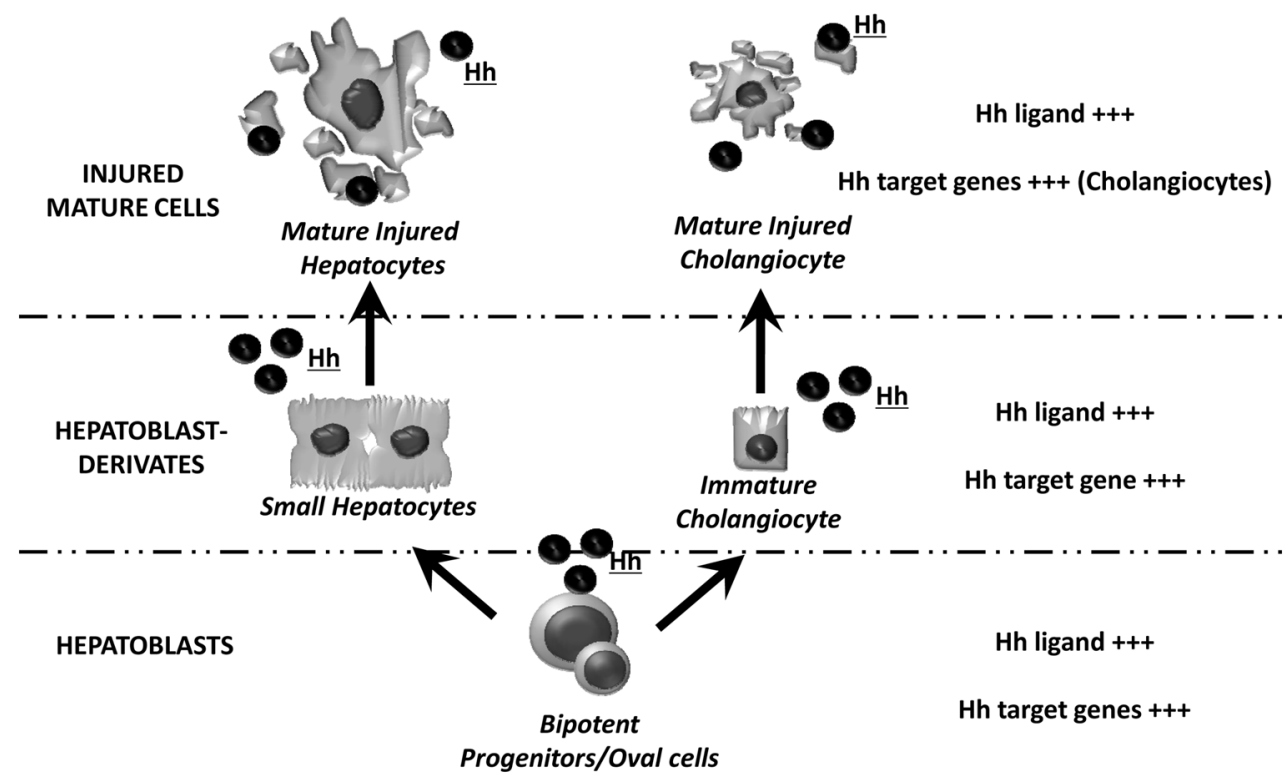

Figure 1. Hedgehog Pathway components in hepatoblasts, hepatoblast-derivates and mature liver epithelial cells

(A-B) Liver progenitor cells give rise to progeny that eventually differentiate into either hepatocytes or cholangiocytes. Herein we refer to both rodent and human bipotent progenitor cells as hepatoblasts (lower level), and their immature progeny as hepatoblastderivatives (middle level). Small hepatocytes and immature ductular cells are hepatoblastderivatives. Both hepatoblasts and hepatoblast-derivatives express Hh ligands and Hh target genes. (A) In uninjured livers, mature cholangiocytes exhibit weak expression of both Hh ligands and $\mathrm{Hh}$ target genes, whereas these factors are never demonstrated in mature hepatocytes (B) In injured livers, cholangiocytes begin to produce Hh ligands and strongly express Hh target genes, while hepatocytes acquire the ability to release Hh ligands. 


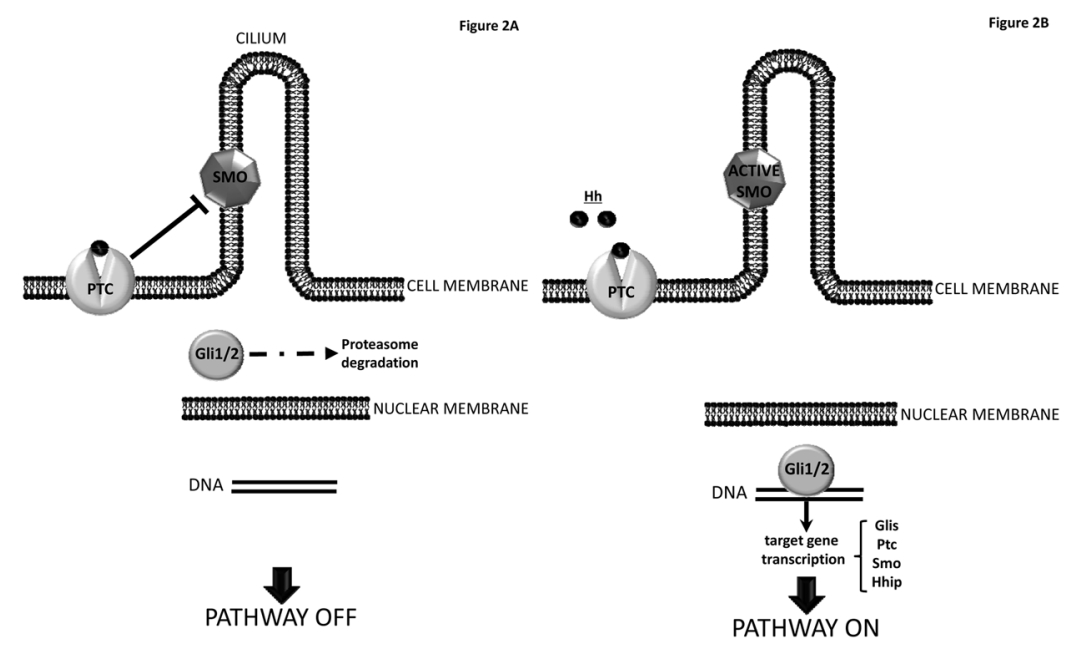

Figure 2. Hedgehog Pathway intracellular signaling

(A) PATHWAY OFF. In absence of Hedgehog ligands (Hh), Patched (Ptc), a membranespanning receptor on the surface of Hh-responsive cells, keeps the co-receptor Smoothened (Smo) in its inactive form. "Free"-Ptc silences the Smo-dependent down-stream intracellular signaling, and Hh-regulated transcription factors undergo multiple phosphorylations, leading to their inactivation and proteasome degradation. Thus, nuclear translocation of Hhregulated transcription factors is prevented, and the pathway is OFF. (B) PATHWAY ON. When the extracellular microenviroment becomes enriched with soluble $\mathrm{HH}$ ligands, they bind to the receptor PTC and this interaction SMO, which turns into its active form. Activation of Smo inhibits Hh transcription factor degradation, leading to an intracellular signaling cascade that ultimately drives the activation and nuclear translocation of Gli family zinc-finger transcription factors, which induce the expression of Hh target genes (e.g. Glis, Ptc, Smo and Hh interactive protein, Hhip). 


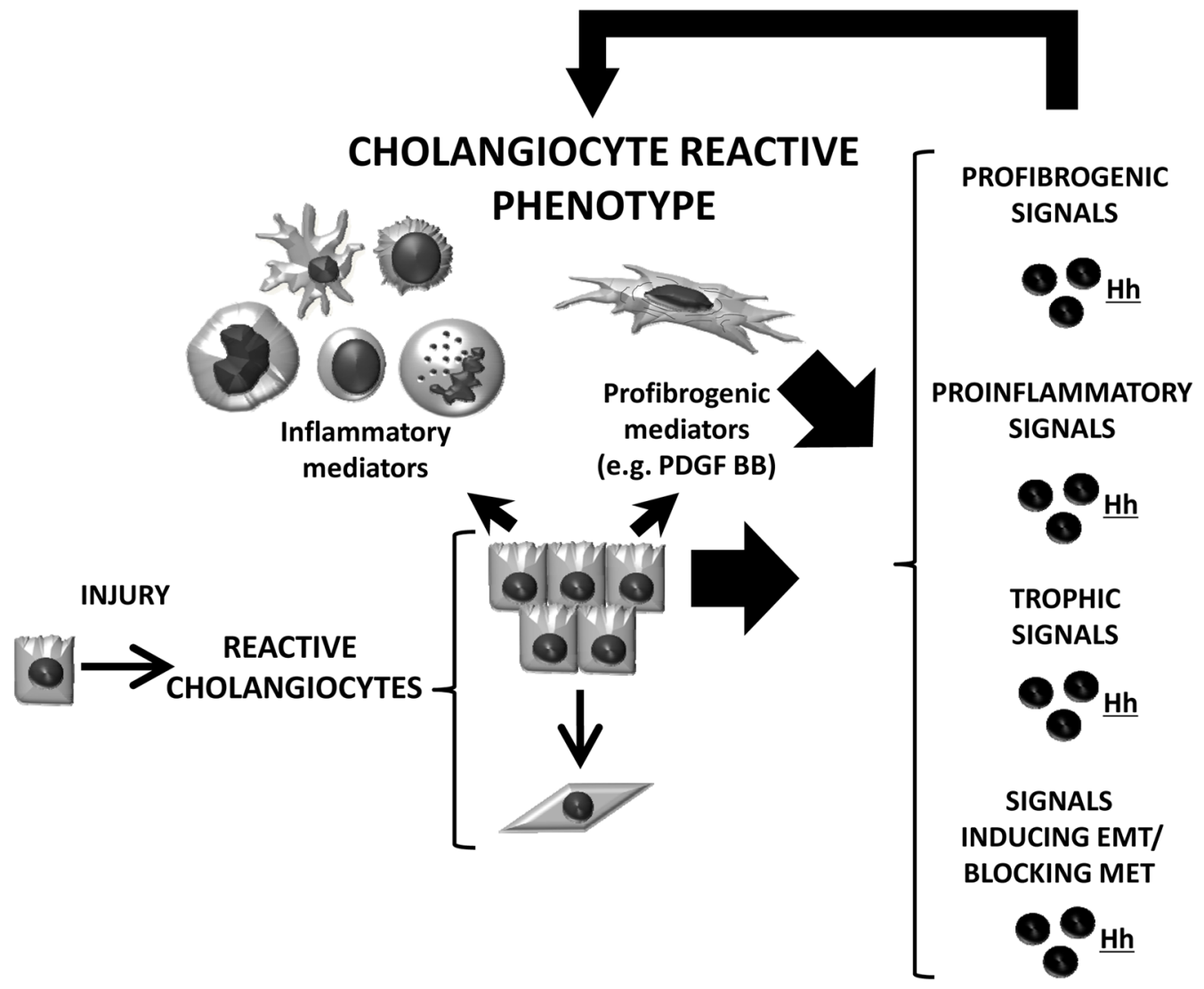

Figure 3. Hedgehog Pathway and cholangiocyte reactive phenotype

When an insult occurs, cholangiocytes acquire the so called "reactive phenotype" which has 4 key features: (1) reduced apoptosis/increased proliferation (which results in the expansion of ductular cell populations); (2) enhanced secretion of chemokines and cytokines (which recruit immune cells promoting periductular inflammation); (3) generation of pro-fibrogenic factors such as PDGFBB (that drive the accumulation and activation of matrix producing myofibroblasts); (4) loss of epithelial features and gain of more mesenchymal phenotype, so-called Epithelial-to-Mesenchymal Transition, EMT (which blocks epithelial differentiation and contributes to biliary fibrosis). These reactive cholangiocytes and the cells that they recruited produce Hh ligands. The Hh ligands, in turn, feedback and reenforce the reactive ductular phenotype by acting as a) profibrogenic, b) proinflammatory, c) trophic, and d) EMT inducing signals. The Hh-enriched microenvironment thus perpetuates the ductular reaction. Because the Hh pathway drives the acquisition/ perpetuation of a reactive phenotype in cholangiocytes, it is now recognized as a key player in all conditions characterized by cholangiocyte activation and ductular reaction. 
Table 1

Recent advances in understanding the effects of Hedgehog pathway activation on biliary epithelial cells

\begin{tabular}{|c|c|c|c|}
\hline Year & Reference & Major Findings & Clinical Relevance \\
\hline 2003 & $\begin{array}{l}\text { Berman DM et al., } \\
\text { Nature }\end{array}$ & Hh transcriptional activity is demonstrated in cholangiocarcinoma cell lines. & Cholangiocarcinoma \\
\hline 2007 & $\begin{array}{l}\text { Omenetti A et al., Lab } \\
\text { Investigation }\end{array}$ & $\begin{array}{l}\text { Murine cholangiocytes: } \\
\text { - } \quad \text { produce Shh and Ihh ligands; } \\
\text { - } \quad \text { are Hh-responsive; } \\
\text { decreased apoptosis) in response to MF-derived Hhligands. } \\
\text { Hh pathway activity increases in murine model of biliary fibrosis. } \\
\text { Mice with overly active Hh pathway display aberrant responses to } \\
\text { experimental cholestasis. }\end{array}$ & Biliary fibrosis \\
\hline 2007 & $\begin{array}{l}\text { Jung Y et al., } \\
\text { Hepatology }\end{array}$ & $\begin{array}{l}\text { Immunohistochemical analysis of human samples from patients with PBC } \\
\text { demonstrates: } \\
\text { - bile ductular cells to strongly express Ihh ligand and the Hh } \\
\text { receptor Ptc, and the Hh target gene Gli2; } \\
\text { - Ihh producing and Hh responsive cells mostly reside among } \\
\text { hepatic progenitor populations. }\end{array}$ & $\mathrm{PBC}$ \\
\hline 2008 & $\begin{array}{l}\text { Jung Y et al., } \\
\text { Gastroenterology }\end{array}$ & $\begin{array}{l}\text { Accumulation of bile ductular cells expressing Hh target genes (Gli2 and Ptc) } \\
\text { is demonstrated by IHC in high fat diet or EtOh fed mice; } \\
\text { Ductular cells that co-express epithelial keratins and mesenchymal markers } \\
\text { are Hh-responsive in human samples from ALD patients. } \\
\text { Accumulation of immature ductular cells correlates with predictors of } \\
\text { survival in patients with severe ALD. }\end{array}$ & ALD \\
\hline 2008 & Omenetti A et al., Gut & $\begin{array}{l}\text { Shh and Ihh ligands are differentially expressed during induction and reversal } \\
\text { of biliary ostruction, suggesting distinct roles for each ligand during injury/ } \\
\text { remodeling phases. } \\
\text { Liver expression of the Hh inhibitor Hhip dramatically declines during biliary } \\
\text { obstruction in rats, and it remains below control levels even at } 12 \text { weeks post- } \\
\text { biliary decompression. } \\
\text { Pattern of pan-cytokeratin and Gli2(+) cells shifts from ductular to } \\
\text { hepatocytic cells during the early recovery period from cholestatic liver } \\
\text { injury. } \\
\text { PDGF-BB induces Shh expression in cholangiocytes while treatment with } \\
\text { recombinant Shh inhibits cholangiocyte apoptosis. }\end{array}$ & Biliary fibrosis, $\mathrm{PBC}$ \\
\hline 2008 & Omenetti A et al., JCI & $\begin{array}{l}\text { Ductular cells that co-express epithelial keratins and mesenchymal markers } \\
\text { are Hh-responsive in human samples from PBC patients. } \\
\text { Hh-responsive freshly isolated rat cholangiocytes from experimental } \\
\text { cholestasis up-regulate the expression of mesenchymal markers. } \\
\text { Murine cholangiocyte cell line exposed to MF- derived Hh ligands acquire } \\
\text { mesenchymal markers and become motile. }\end{array}$ & Biliary fibrosis, $\mathrm{PBC}$ \\
\hline 2009 & $\begin{array}{l}\text { Witek RP et al., } \\
\text { Gastroenterology }\end{array}$ & $\begin{array}{l}\text { PDGFBB induces cholangiocytes to release exosome-enriched microparticles } \\
\text { containing biologically active Hh ligands. } \\
\text { Experimental biliary obstruction determines accumulation of microparticles } \\
\text { containing biologically active Hh ligands in plasma and bile }\end{array}$ & Biliary fibrosis, Cirrhosis \\
\hline 2009 & $\begin{array}{l}\text { Syn WK et al., } \\
\text { Gastroenterology }\end{array}$ & $\begin{array}{l}\text { Ductular cells in human samples from NASH patients strongly express Shh } \\
\text { ligand, the Hh target gene Gli2, and acquire mesenchymal markers. } \\
\text { Hh pathway activation correlates with severity of disease in NAFLD. }\end{array}$ & NAFLD \\
\hline 2010 & $\begin{array}{l}\text { Ochoa B et al., } \\
\text { Hepatology }\end{array}$ & $\begin{array}{l}\text { Bile ductular cells express Hh target genes after Partial Hepatectomy(PH)in } \\
\text { mice. }\end{array}$ & Liver regeneration \\
\hline 2010 & $\begin{array}{l}\text { Pereira } \mathrm{T} \text { et al, Lab } \\
\text { Investigation }\end{array}$ & $\begin{array}{l}\text { Ductular cells in human samples from patients with Hepatitis B and C } \\
\text { strongly express Shh ligand, the Hh target gene Gli2. } \\
\text { Hh responsive cells within the ductular reaction in viral hepatitis co-express } \\
\text { markers of liver epithelial progenitors mesenchymal cells }\end{array}$ & Viral hepatitis \\
\hline 2010 & $\begin{array}{l}\text { Kurita S et al., } \\
\text { Oncogene }\end{array}$ & Cholanciocarcinoma cells have canonical Hh pathway: & Cholangiocarcinoma \\
\hline
\end{tabular}




\begin{tabular}{|c|c|c|c|}
\hline Year & Reference & Major Findings & Clinical Relevance \\
\hline & & $\begin{array}{l}\text { mRNA of all three ligands (Shh, Ihh, Dhh) are found to be } \\
\text { expressed in cholangiocarcinoma cell lines, with differential Shh/ } \\
\text { Ihh ratio in each line; } \\
\text { expression of the cell surface proteins Smo and Ptc is found in all } \\
\text { lines; } \\
\text { the } 3 \text { cell lines examined and } 47 \text { human cholangiocarcinoma } \\
\text { samples express transcripts of Hh target genes; } \\
\text { Blockage of Hh signaling sensitizes cholangiocarcinoma cell line to TRAIL- } \\
\text { induced apoptosis by upregulating DR4. } \\
\text { Hh silencing of the DR4 promoter requires intact Gli-binding sites. }\end{array}$ & \\
\hline 2010 & $\begin{array}{l}\text { Mott JL et al., JCB } \\
2010\end{array}$ & $\begin{array}{l}\text { Functional Gli binding sites are demonstrated in the miR-29b promoter; } \\
\text { Glirepresses transcriptional activity of miR-29b; } \\
\text { activation of Hh signaling protects non-malignant cholangiocytes from } \\
\text { TRAIL induced apopotosis. }\end{array}$ & Cholangiocarcinoma \\
\hline 2011 & $\begin{array}{l}\text { Omenetti et al., } \\
\text { Hepatology }\end{array}$ & $\begin{array}{l}\text { Cholangiocytes from pediatric non-diseased subjects show greater innate Hh } \\
\text { activation than adult controls; } \\
\text { excessive accululation of Hh-producing/- responsive cells occurs in infantile } \\
\text { cholestatic disease; } \\
\text { Hh-mediated EMT contribute to biliary dysmorphogenesis in Biliary Atresia. }\end{array}$ & $\begin{array}{l}\text { Biliary Atresia, PFIC- } \\
\text { FIC1/FIC2, Alagille } \\
\text { Syndrome }\end{array}$ \\
\hline
\end{tabular}

